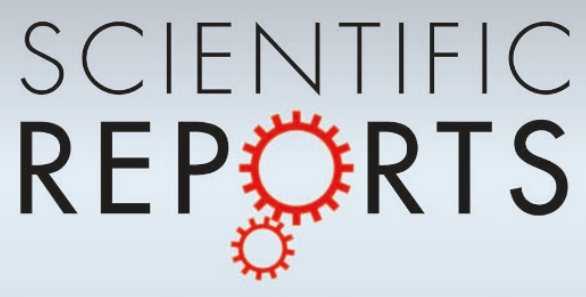

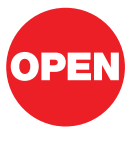

SUBJECT AREAS:

MECHANICAL

PROPERTIES

DNA NANOSTRUCTURES

FERROMAGNETISM

ELECTRONIC AND SPINTRONIC

DEVICES

Received

29 January 2013

Accepted

23 April 2013

Published

10 May 2013

Correspondence and requests for materials should be addressed to W.N.K. (wnkang@ skku.edu) or S.H.P. (sunghapark@skku.

edu)

\section{Magnetic Characteristics of Copper lon-Modified DNA Thin Films}

\author{
Sreekantha Reddy Dugasani 1,2, Namhoon Lee', Junwye Lee ${ }^{2}$, Byeonghoon Kim², Si Un Hwang', \\ Keun Woo Lee ${ }^{1,2}$, Won Nam Kang' \& Sung Ha Park ${ }^{1,2}$
}

'Department of Physics, Sungkyunkwan University, Suwon 440-746, Korea, ${ }^{2}$ Sungkyunkwan Advanced Institute of
Nanotechnology (SAINT), Sungkyunkwan University, Suwon 440-746, Korea.

We developed a new method of fabricating a divalent copper ion $\left(\mathrm{Cu}^{2+}\right)$ modified DNA thin film on a glass substrate and studied its magnetic properties. We evaluated the coercive field $\left(H_{c}\right)$, remanent magnetization $\left(M_{r}\right)$, susceptibility $(\chi)$, and thermal variation of magnetization with varying $\mathrm{Cu}^{2+}$ concentrations $\left[\mathrm{Cu}^{2+}\right]$ resulting in DNA thin films. Although thickness of the two dimensional DNA thin film with $\mathrm{Cu}^{2+}$ in dry state was extremely thin $(0.6 \mathrm{~nm})$, significant ferromagnetic signals were observed at room temperature. The DNA thin films with a $\left[\mathrm{Cu}^{2+}\right]$ near $5 \mathrm{mM}$ showed the distinct S-shape hysteresis with appreciable high $H_{c}, M_{r}$ and $\chi$ at low field ( $\leq 600 \mathrm{Oe}$ ). These were primarily caused by the presence of small magnetic dipoles of $\mathrm{Cu}^{2+}$ coordination on the DNA molecule, through unpaired $d$ electrons interacting with their nearest neighbors and the inter-exchange energy in the magnetic dipoles making other neighboring dipoles oriented in the same direction.

D NA nanotechnology, a rapidly emerging field with practical applications, is of great interest for self-assembly structural design and growth on various substrates inspiring potential applications in spintronics $^{1,2}$, nanoelectronics ${ }^{3,4}$, biosensors ${ }^{5,6}$ and nanophotonics ${ }^{7,8}$. Structural DNA nanotechnology has been recognized as an interdisciplinary field, with researchers from engineering, physical, biological and medical sciences uniting to create an interesting multidisciplinary research area ${ }^{9,10}$. Over the last few decades, researchers noticed that metal ion modified DNA (M-DNA) nanostructures had vast potential applications in spintronics as well as nanoelectronics. The incorporation of copper ion $\left(\mathrm{Cu}^{2+}\right)$ into DNA allows the transfer of functionality, such as thermal, electrical, magnetic, optical ${ }^{11}$ and even redox chemical properties. However, the selective incorporation of metals into DNA molecules has to be considered carefully because excess metals can bind non-specifically and even cleave biomolecules.

Improvement of the memory storage capacity, low power consumption and rapid information process rely not only on the charges, but also the spin, quantum mechanical properties of electrons. The most efficient way to manipulate spins is by coupling a magnetic field directly with the intrinsic magnetic moments of electrons, or through the spin orbit interaction, either externally applied or existing inside a ferromagnetic material. The concept of using single strand or duplex DNA molecules with metal ions was studied previously ${ }^{12-15}$, but an artificially designed M-DNA nanostructure has not often been reported due to the structural stability. M-DNA nanostructures with a controllable metal ion concentration are a novel idea in the field of advanced spintronics and electronics. For example, several thought have been proposed to build a spin valve by sandwiching a layer of DNA thin films between two ferromagnetic layers or an organic solar cell as an electron blocking layer between organic and polymer layers ${ }^{16}$. DNA molecules have diverse electronic properties depending on their structure and environmental effect ${ }^{17}$.

Several reports explained the magnetic properties of analytes in the form of single and duplex M-DNA through a superconducting quantum interference device (SQUID) and an electron spin resonance (ESR), but not in the form of artificially designed tile-based $2 \mathrm{D}$ polycrystalline crystals initially grown on a given substrate. In this article, we report the magnetic properties of self-assembled double-crossover (DX) DNA thin films coordinated with $\mathrm{Cu}^{2+}$. Samples are prepared by substrate-assisted growth (SAG) method which produces completely covered DNA thin films on various substrates such as mica, piranha-treated glass (PG) using electrostatic interactions ${ }^{18-20}$. Growth on the glass is cost-effective and feasible for specific device applications, especially in magnetic devices, because the glass exhibits diamagnetism at room temperature. 


\section{Results}

We evaluated the preliminary magnetic properties of $\mathrm{Cu}^{2+}$-DNA complexes on a mica substrate with an atomic force microscope (AFM) and a SQUID. Mica is commonly used in biological imaging due to the existence of intrinsic net charge and atomically flattened nature. However, estimating the magnetic nature of DNA and $\mathrm{Cu}^{2+}$ DNA is difficult because mica consists of ferromagnetic impurities and has been shown to have strong ferromagnetism (for details, see Fig. S1 in Supplementary Information). DNA molecular magnetism may be caused by the accidental inclusion of unwanted ferromagnetic impurities and intentionally induced through stoichiometric binding or the coordination of transition metal ions. Magnetic field $(H)$-dependent magnetic moment $(m), m-H$ was performed at room temperature to understand the magnetism of the $\mathrm{Cu}^{2+}$ in modified DNA complexes. The AFM image of DNA thin films formed by multiple unit building blocks of $\mathrm{DX}^{21}$ on mica, $m-H$ curves of pure mica and $5 \mathrm{mM} \mathrm{Cu}^{2+}$ concentration $\left[\mathrm{Cu}^{2+}\right]$ in DNA are shown in Fig. S1. The mica sheet exhibited a hysteresis loop because of ferromagnetic impurities such as $\mathrm{Cr}$ and $\mathrm{Fe}$ that were commonly present. The $\mathrm{Cu}^{2+}$-DNA complex showed less $H_{c}$ and $m$ compared with the mica as reference, indicating that the $\mathrm{Cu}^{2+}$-DNA complex without mica also strongly influenced magnetic properties and both ferromagnetic and antiferromagnetic interactions existed in this complex. The decrease of the $m$ with $\left[\mathrm{Cu}^{2+}\right]$ can be attributed to the change of antiferromagnetic and ferromagnetic interactions, which may originate from the carrier density change due to impurities on the substrate and $\mathrm{Cu}^{2+}$ coordination. Consequently, estimating the $\chi(=M / H)$ and magnetism of $\mathrm{Cu}^{2+}$-DNA complex with the mica substrate was difficult. In order to overcome undesirable substrate effect of mica, a glass substrate was introduced for better magnetic property analysis.

DNA DX polycrystalline structures were fabricated on glass by the SAG method. The schematic diagram of a DX tile and thin films are shown in Fig. 1a. Two DX tiles (see Fig. S2 and Tables S1, S2) were used for the construction of the 2D DNA crystal structure on the given substrate and the detailed sample preparation is explained in Methods. Polycrystalline DNA nanostructures fabricated with different $\left[\mathrm{Cu}^{2+}\right]$ showed high dependence of DNA base pairings to the $\mathrm{pH}$ of the physiological buffer solution. Experimental procedures were adopted by adding $\mathrm{Cu}^{2+}$ into the DNA buffer solution before and after the DNA hybridization annealing in order to evaluate the structural stability of DNA with the various $\left[\mathrm{Cu}^{2+}\right]$. The experimental schematic of adding $\mathrm{Cu}^{2+}$ before and after annealing is shown in Fig. S3. For consistency, other circumferential parameters, i.e., thermal energy controlled by an annealing time of 24 hours, the electrostatic interaction between the substrate and DNA molecules by the substrate size $3 \times 3 \mathrm{~mm}^{2}$ and total volume of $130 \mu \mathrm{L}$ in a test tube, were fixed during the annealing process, whereas various concentrations of $\mathrm{Cu}^{2+}$ were used as a control parameter.

The $\mathrm{Cu}^{2+}$ are intercalated between bases and bound with phosphate backbone sites shown in Fig. $1 \mathrm{a} . \mathrm{Cu}^{2+}$ bindings were verified by current measurement, chemical reduction method ${ }^{22}$, or Raman measurement. From Raman data, we noticed that binding preferences for $5 \mathrm{mM}\left[\mathrm{Cu}^{2+}\right]$ are roughly $50 \%$ into AT, 30\% into GC base pairs and $20 \%$ into $\mathrm{PO}_{4}^{-}$sites. Fig. $1 \mathrm{~b}$ shows an AFM image of the DNA thin films without a $\mathrm{Cu}^{2+}(\mathrm{Cu} 0)$ and the inset in the top right is the noisefiltered 2D spectrum image obtained from fast Fourier transform showing the periodicity of the unit building blocks. Fig. 1c shows the DNA thin films with $20 \mathrm{mM}\left[\mathrm{Cu}^{2+}\right]\left(\right.$ the $\mathrm{Cu}^{2+}$ was added after annealing). In this approach, $\left[\mathrm{Cu}^{2+}\right]$ up to $20 \mathrm{mM}$ used with the DNA showed that surface morphology was unchanged because the electrostatic force between substrate and DNA thin films became more intense after growth on the substrate. More AFM images after addition of different $\left[\mathrm{Cu}^{2+}\right]$ are shown in Fig. S4. In contrast, Figs. 1d-1f show AFM images of the 5, 8 and $15 \mathrm{mM}\left[\mathrm{Cu}^{2+}\right]$ where the $\mathrm{Cu}^{2+}$ used with the DNA was added before annealing. In this case, the surface morphological changes and amorphous/aggregated structures were observed at higher $\left[\mathrm{Cu}^{2+}\right]$. The surface morphologies of M-DNA thin films formed with 0-6 $\mathrm{mM}\left[\mathrm{Cu}^{2+}\right]$ showed similar structures as normal DNA thin films. The DNA thin films formed with 6-8 $\mathrm{mM}\left[\mathrm{Cu}^{2+}\right]$ appeared as smaller crystal fragments, whereas DNA thin films formed with greater than $10 \mathrm{mM}\left[\mathrm{Cu}^{2+}\right]$ showed amorphous structures without crystal domain boundaries. In this report, we focused on magnetic properties of $\mathrm{Cu}^{2+}$-modified DNA thin films without structural deformation.

The variation of $m$ and magnetization $(M)$ with $H, m-H$ and $M-H$ curves for the DNA samples with various $\left[\mathrm{Cu}^{2+}\right]$ of $0,3,5,10$ and $20 \mathrm{mM}$ incorporated in the DX thin films on PG, $5 \mathrm{mM}\left[\mathrm{Cu}^{2+}\right]$ in the physiological $1 \times \mathrm{TAE} / \mathrm{Mg}^{2+}$ buffer on PG and a PG substrate are shown in Fig. 2. Fig. 2a shows the $m-H$ curves which included the $m$ of pristine PG substrate in all samples. The $M-H$ curves for $5 \mathrm{mM}$ $\left[\mathrm{Cu}^{2+}\right]$ without DNA (the $m$ values of PG have been subtracted) is

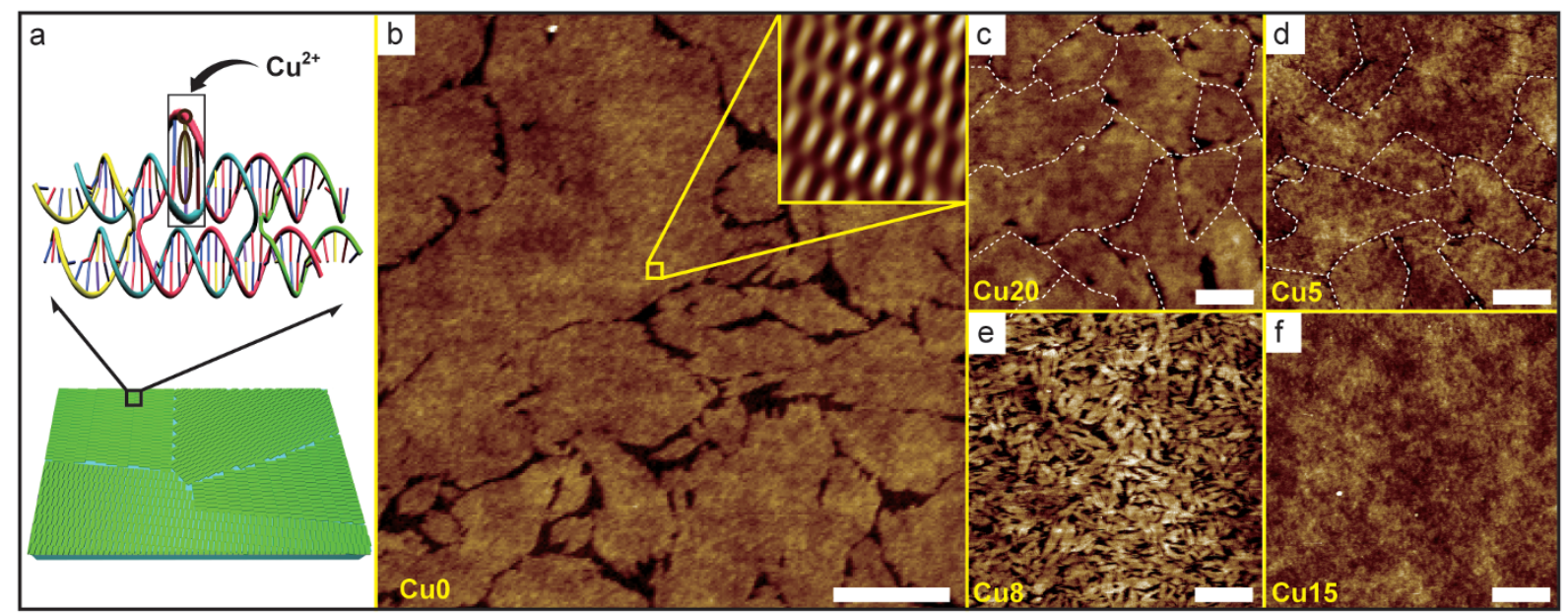

Figure 1 Schematic diagram and AFM images of M-DNA thin films. (a) Schematic view of DNA double-crossover (DX) crystal fabrication by the substrate-assisted growth (SAG) method. Schematic diagrams reveal the DNA DX polycrystals on piranha-treated glass (PG) substrate and DX unit motif. In magnified duplex in DX motif, black circles are sites for $\mathrm{Cu}^{2+}$ coordination. (b) AFM image of DNA without the $\mathrm{Cu}^{2+}(\mathrm{Cu} 0)$. The inset in the top right is the noise-filtered 2D spectrum image $\left(\right.$ scan size, $50 \times 50 \mathrm{~nm}^{2}$ ) by fast Fourier transform which shows the periodicity of the thin films.

(c) The DNA thin films with $20 \mathrm{mM}\left[\mathrm{Cu}^{2+}\right]$ (Cu20) (the $\mathrm{Cu}^{2+}$ was added after annealing). (d-f) AFM images of the DNA with Cu${ }^{2+}$ ions of concentration 5, 8 and $15 \mathrm{mM}\left(\mathrm{Cu} 5, \mathrm{Cu} 8\right.$, and $\mathrm{Cu} 15$ respectively) (the $\mathrm{Cu}^{2+}$ was added before annealing). Scale bars in all AFM images are $500 \mathrm{~nm}$. 

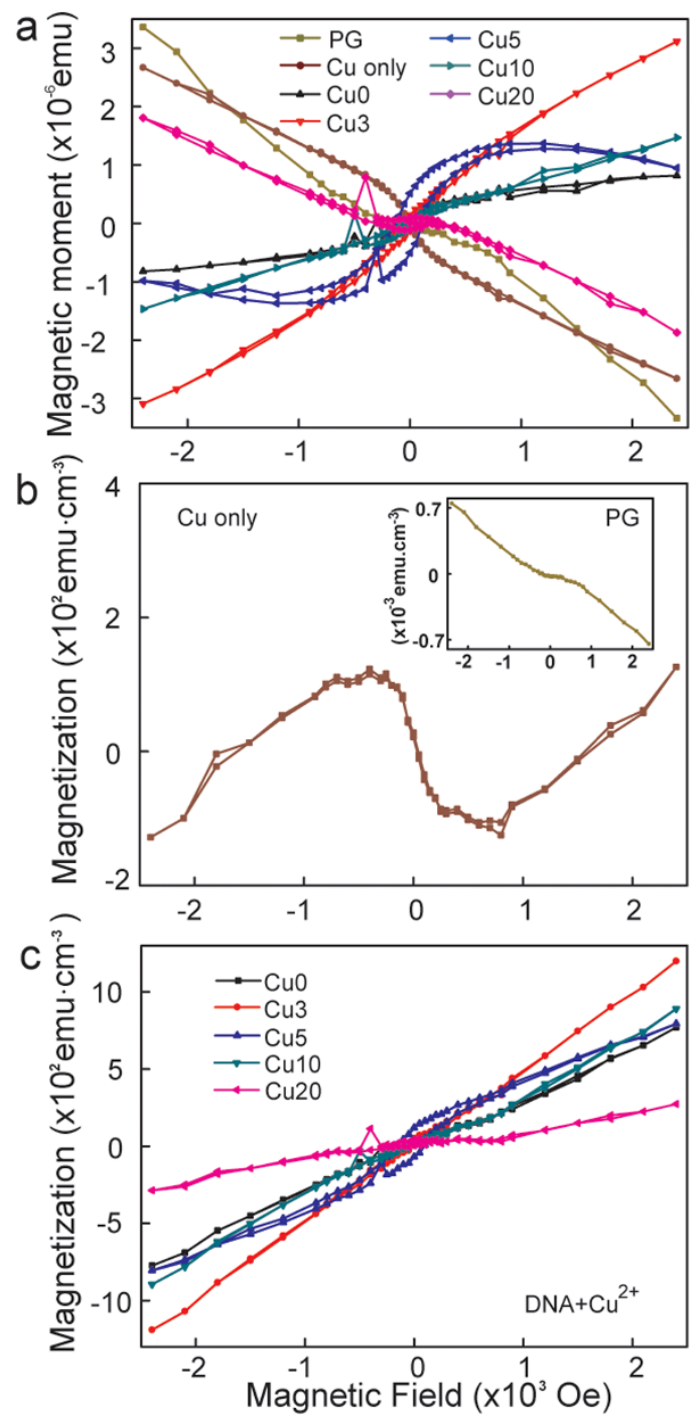

Figure $2 \mid$ Magnetization of the copper ion modified DNA thin films. (a) The variation of magnetic moment with magnetic field, $m-H$ for piranha- treated glass $(\mathrm{PG}), 5 \mathrm{mM}\left[\mathrm{Cu}^{2+}\right]$ in $1 \times \mathrm{TAE} / \mathrm{Mg}^{2+}$ without DNA on PG (Cu Only) and various $\left[\mathrm{Cu}^{2+}\right]$ DNA complexes. (b) The $M-H$ curves for $5 \mathrm{mM}\left[\mathrm{Cu}^{2+}\right]$ alone (Cu Only) and inset showing the pristine PG substrate. (c) $M-H$ curves for various $\left[\mathrm{Cu}^{2+}\right]$ used in the DNA thin films (the values shown are with the $m$ values of PG subtracted) with ion concentrations $0,3,5,10$ and $20 \mathrm{mM}$ marked as $\mathrm{Cu} 0, \mathrm{Cu} 3, \mathrm{Cu} 5, \mathrm{Cu} 10$ and $\mathrm{Cu} 20$ respectively.

shown in Fig. $2 b$ and the inset shows the pristine PG substrate. These graphs indicate the diamagnetism at room temperature, as expected. Interestingly, the sample with greater than 1500 Oe showed a magnetic transition. Fig. 2c shows the $M$ data of $\mathrm{Cu}^{2+}$-modified DNA complexes with the $m$ data of pristine PG substrate subtracted from the original data shown in Fig. 2a. We first subtracted the $m$ of PG from $m$ of all various $\left[\mathrm{Cu}^{2+}\right]$ used in the DNA complexes and then calculated the $M$. Here magnetization is defined as magnetic moment per unit volume, $M=m / V$. The dimensions of PG and DNA on the PG substrate were $0.3 \times 0.3 \times 0.05 \mathrm{~cm}^{3}$ and $0.3 \times 0.3 \times(6 \times$ $\left.10^{-8}\right) \mathrm{cm}^{3}$ (length $\times$ width $\times$ thickness), respectively. Although the 2D DNA structure had a very thin layer of $0.6 \mathrm{~nm}$ in dry state ${ }^{23,24}$, all $\mathrm{Cu}^{2+}$-DNA complexes showed ferromagnetism at room temperature due to $\mathrm{Cu}^{2+}$ binding with DNA molecules. The noticeable $H_{c}$, $M_{r}$ and magnetization saturation $\left(M_{s}\right)$ of $M-H$ hysteresis loop for various $\left[\mathrm{Cu}^{2+}\right]$ used with the DNA could be attributed to strong ferromagnetic ordering and were greatly enhanced up to $5 \mathrm{mM}$ and then decreased with increasing $\left[\mathrm{Cu}^{2+}\right]$. This trend indicates that the saturation concentration of $\mathrm{Cu}^{2+}$ coordination on DNA molecules is about $5 \mathrm{mM}$ in the $\mathrm{Cu}^{2+}$-DNA complex.

\section{Discussion}

The ferromagnetic behavior could be attributed to the presence of small magnetic dipoles of $\mathrm{Cu}^{2+}$ located inside the DNA bases, which interact with their nearest neighbors inside the DNA molecules. In this case, the inter-exchange energy in magnetic dipoles probably caused other neighboring dipoles to be oriented in the same direction. With the increase of $\left[\mathrm{Cu}^{2+}\right]$ in the DNA, the $\mathrm{Cu}^{2+}$ atoms may come closer to each other and excess $\mathrm{Cu}^{2+}$ cannot bind with the DNA bases. The $M_{s}$ and $\chi$ decreased due to the distance between the $\mathrm{Cu}^{2+}$ decreasing as the $\left[\mathrm{Cu}^{2+}\right]$ increased. According to the $\mathrm{Cu}^{2+}$ DNA complex, the number of copper atoms can strongly affect the magnetic properties of the system ${ }^{11}$. Possibly, an increased $\left[\mathrm{Cu}^{2+}\right]$ (number of $\mathrm{Cu}^{2+}$ ) occupying adjacent positions results in antiferromagnetic alignment. The competition between the ferromagnetism and antiferromagnetism leads to the decrease in S-shape hysteresis, $M_{s}$ and $\chi$ at higher $\left[\mathrm{Cu}^{2+}\right]$, implying that the distance between nearest neighbor $\mathrm{Cu}^{2+}$ plays an important role in the origin of the magnetism. Consequently, the quantitative amount of ferromagnetic dipoles and number of dipoles oriented in the same direction or number of parallel spins/length of the $\mathrm{Cu}^{2+}$ chain can be reduced due to unbinding or excess of $\mathrm{Cu}^{2+}$ in the $\mathrm{Cu}^{2+}$-DNA complex. Because of this fact, $M_{s}, H_{c}$ and $M_{r}$ were reduced for higher $\left[\mathrm{Cu}^{2+}\right]$ and clearly identified for 10 and $20 \mathrm{mM}$ in contrast with the $5 \mathrm{mM} \mathrm{Cu}^{2+}$-DNA complexes.

An earlier report explains that $\lambda$-DNA exhibits paramagnetic behavior below $20 \mathrm{~K}$ and the results showed the interplay between the molecular structures and their magnetic properties and the proposed orbital paramagnetism as the origin of the observed phenomena $^{25}$. In most M-DNAs, the valence of metal ions is two, corresponding to the simple ion exchange by a divalent metal in place of two $\mathrm{Na}^{+}$counter cations for $\left(\mathrm{PO}_{4}^{-}\right)$anions. When the zinc ions $\left(\mathrm{Zn}^{2+}\right)$ in $\mathrm{Zn}^{2+}$-DNA complexes are prepared by a freeze-dry method, the possible electronic states of $\mathrm{Zn}^{2+}$ are the covalent bonding of $\mathrm{Zn}^{2+}$ with the nitrogen atoms of the bases under the extremely dried condition ${ }^{26}$. In addition, one to five $\mathrm{Cu}^{2+}$-mediated base pairs of hydroxypyridone nucleobases were systematically incorporated into the middle of a DNA duplex in the solution phase, resulting in the formation of a magnetic chain by the line-up and the $\mathrm{Cu}^{2+}$ in each complex coupling ferromagnetically with one another through unpaired $d$ electrons ${ }^{11}$. The variation of hysteresis loop in the $\mathrm{Cu}^{2+}$ DNA complexes revealed the ferromagnetic nature, which reflects the evidence of $\mathrm{Cu}^{2+}$ binding with DNA molecules and spin alignment of the highly ionic $\mathrm{Cu}^{2+}$ in the DNA molecules. Hypothetically, the binding nature of the $\mathrm{Cu}^{2+}$ was hydrated by several water molecules in between the bases of a base pair and spins parallel-aligned to form long chains in ferromagnetic complexes. This requirement was due to the preference of $\mathrm{Cu}^{2+}$ to form the covalent bond with the nitrogen atoms of a base pair.

The variations of $H_{c}$ and $M_{r}$ with $\left[\mathrm{Cu}^{2+}\right]$ used in the DNA thin films are shown in Fig. 3 a with highest $H_{c}$ and $M_{r}$ at $5 \mathrm{mM}\left[\mathrm{Cu}^{2+}\right]$. The variation of $\chi$ estimated for $\mathrm{Cu}^{2+}$ without DNA complexes and $\mathrm{Cu}^{2+}$-DNA complexes with different $\left[\mathrm{Cu}^{2+}\right]$ at a particular magnetic field of 600 Oe is shown in Fig. 3b and the inset shows the average $\chi$ (slope of $M-H$ curve). The pristine $\mathrm{PG}$ and $5 \mathrm{mM}\left[\mathrm{Cu}^{2+}\right]$ revealed the negative $\chi$, which indicated a diamagnetic nature (diamagnetic $\chi$ of $\mathrm{PG}$ is $\left.-2.66 \times 10^{-7} \mathrm{emu} \cdot \mathrm{cm}^{-3} \cdot \mathrm{Oe}^{-1}\right)$. Average $\chi$ for various $\left[\mathrm{Cu}^{2+}\right]$ used in the DNA thin films showed the positive $\chi$ above the order of $10^{-2} \mathrm{emu} \cdot \mathrm{cm}^{-3} \cdot \mathrm{Oe}^{-1}$ which implied ferromagnetic nature. Increasing $\left[\mathrm{Cu}^{2+}\right]$ up to a certain limit in $\mathrm{Cu}^{2+}$-DNA complexes provided for more chances to have the spins in parallel alignment and formed as magnetic long chains inside DNA duplex. Because of this phenomenon, ferromagnetic $\chi$ was observed with appreciable 

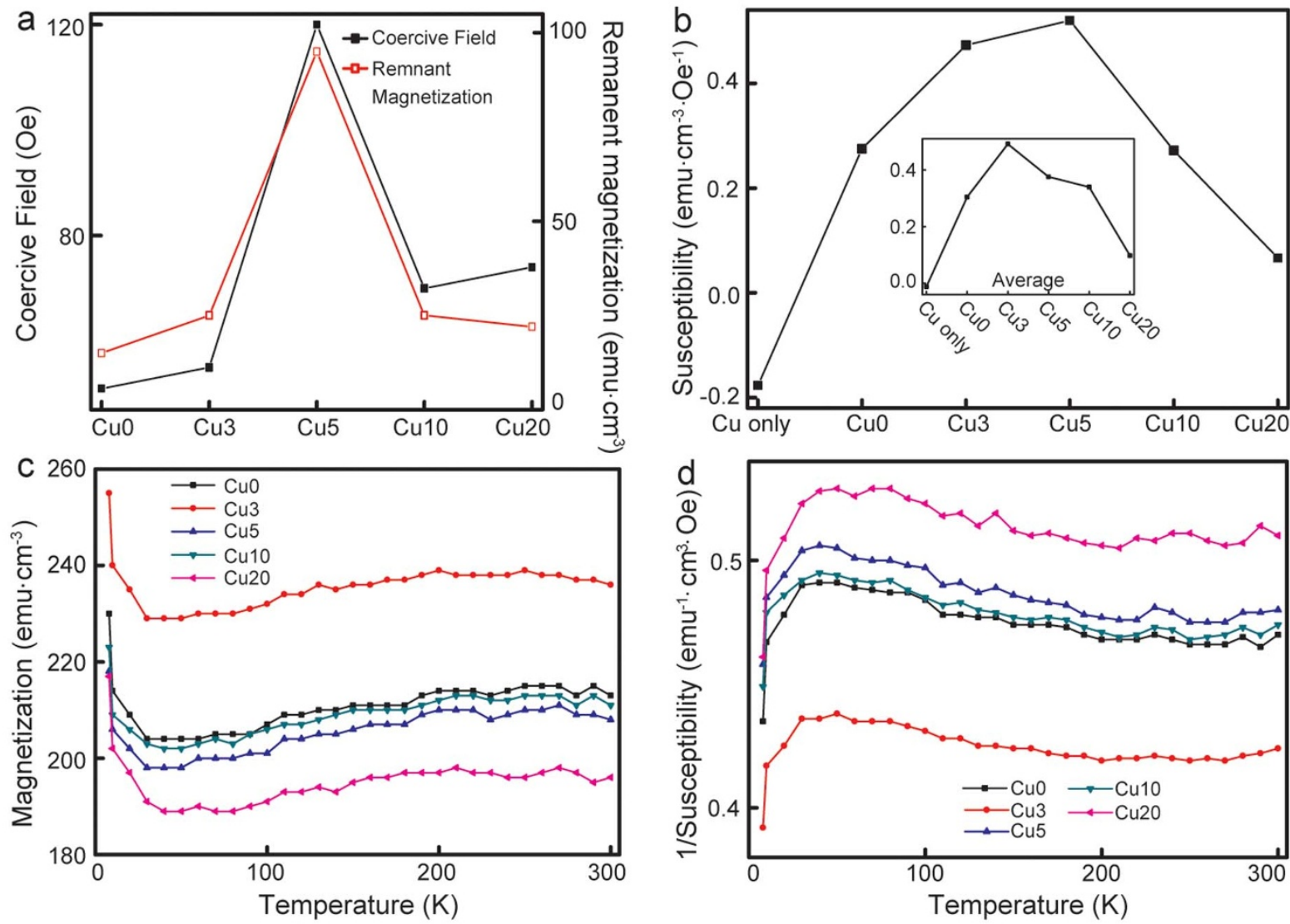

Figure 3 Magnetic characteristics of the copper ion modified DNA thin films. (a) The variation of coercive field $\left(H_{c}\right)$ and remanent magnetization

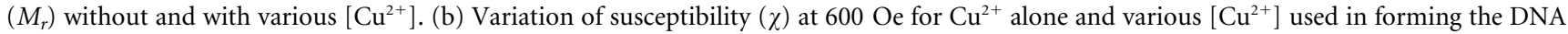
thin films. Inset shows the average $\chi$. (c, d) Temperature dependence of magnetization $(M-T)$ and inverse $\chi\left(\chi^{-1}-\mathrm{T}\right)$ for various [Cu $\left.{ }^{2+}\right]$ DNA complexes. From $M-T$, the nonzero magnetization can be observed and is roughly constant between 20 and $300 \mathrm{~K}$ with no indication of a magnetic transition up to $300 \mathrm{~K}$.

enhancement for $5 \mathrm{mM}\left[\mathrm{Cu}^{2+}\right]$ used in the DNA thin film at $600 \mathrm{Oe}$, and the case of average $\chi$ for $3 \mathrm{mM}\left[\mathrm{Cu}^{2+}\right]$ used in the DNA showed slightly higher $\chi$ compared with $5 \mathrm{mM}\left[\mathrm{Cu}^{2+}\right]$. Afterwards, the $\chi$ above $10 \mathrm{mM}\left[\mathrm{Cu}^{2+}\right]$ used in the DNA thin films decreased and is shown in Fig. 3b. This behavior suggests that the physical properties of $\mathrm{Cu}^{2+}$-DNA complexes such as electric, magnetic and optical could be adjusted according to the $\left[\mathrm{Cu}^{2+}\right]$.

The thermal variation from 8 to $300 \mathrm{~K}$ of $M$ for $\mathrm{Cu}^{2+}$-DNA complexes with a relatively small applied magnetic field (100 Oe) was also investigated and is shown in Fig. 3c. The variation of $M$ with temperature $(T)$ for $5 \mathrm{mM}\left[\mathrm{Cu}^{2+}\right]$ without DNA thin films and PG alone are shown in Fig. S5. We observed ferromagnetic behavior at $300 \mathrm{~K}$ and the nonzero magnetization and roughly constant behavior between 20 and $300 \mathrm{~K}$ with no indication of a magnetic transition up to room temperature. This implies that the Curie temperature for the DNA thin films with $\left[\mathrm{Cu}^{2+}\right]$ was above $300 \mathrm{~K}$. Interestingly, an appreciable increase of the $M$ was observed between 20 and $8 \mathrm{~K}$. The variations of inverse $\chi$ with $T$ for all samples are shown in Fig. 3d. As seen in Fig. 3d, ferromagnetic materials exhibited a downward deviation at low temperatures and the data at high temperatures were linear, since thermal energy was greater than the energy of the magnetic interactions. The SQUID measurements for $\mathrm{Cu}^{2+}$-DNA complexes showed a tendency for a strong ferromagnetic interaction between the neighboring $\mathrm{Cu}^{2+}$ spins.

In conclusion, we constructed fully covered DNA polycrystalline structures with a various divalent $\left[\mathrm{Cu}^{2+}\right]$ on mica and glass substrates by using the SAG method and studied the unique magnetic properties with temperature variations down to $8 \mathrm{~K}$. Approximately DNA thin films with $5 \mathrm{mM}\left[\mathrm{Cu}^{2+}\right]$ exhibited a strong ferromagnetic nature with high $H_{c}$, and $M_{r}$ at room temperature and was a reliable optimum concentration for spintronic devices. The $M-T$ at a higher temperature region showed nonzero magnetization which indicated ferromagnetism with Curie temperature above $300 \mathrm{~K}$. Consequently, magnetic properties of $\mathrm{Cu}^{2+}$ modified DNA nanostructures can provide a bridge between structural biology and physical sciences. Artificially designed DNA nanostructures with various metallic ions will be a new class of material for electronic and magnetic devices, as well as sensors in the near future.

\section{Methods}

Annealing DNA thin films on glass. For sample preparation, a $3 \times 3 \mathrm{~mm}^{2}$ glass substrate was treated with a piranha solution $\left(1: 2\right.$ ratios of $\mathrm{H}_{2} \mathrm{O}_{2}$ and $\mathrm{H}_{2} \mathrm{SO}_{4}$ ) for $30 \mathrm{~min}$. followed by rinsing with DI water for cleaning. Due to piranha treatment, the glass surface changed from hydrophobic to hydrophilic (surface was functionalized with hydroxyl (-OH) group). Synthetic oligonucleotides, purified by high performance liquid chromatography (HPLC) were purchased from Integrated DNA Technologies (IDT, Coralville, IA, USA). The complexes were formed by mixing a 1 $\times \mathrm{TAE} / \mathrm{Mg}^{2+}$ buffer solution, which contained an equimolar mixture of 8 different DX strands. For annealing, the substrate, along with the DNA strands, was inserted into an AXYGEN-tube with a total sample volume of $130 \mu \mathrm{L}$ and then placed in a Styrofoam box with $2 \mathrm{~L}$ of boiled water and cooled slowly from $95^{\circ} \mathrm{C}$ to $25^{\circ} \mathrm{C}$ over a period of at least 24 hours to facilitate the hybridization process. During the annealing process, the DX strands formed polycrystalline DX structures on the substrate and consequently this structure completely covered the glass surface. The sample was prepared with a DX concentration of $70 \mathrm{nM}$ which was well above the saturation concentration of $20 \mathrm{nM}$ for full coverage of DNA thin films on the silica substrate ${ }^{19}$

Copper ion $\left(\mathrm{Cu}^{2+}\right)$ coordination. Before Annealing Method: For $\mathrm{Cu}^{2+}$ modification, $130 \mu \mathrm{L}$ of $70 \mathrm{nM}$ DNA DX strands was mixed with desired concentrations $(0,3,5,10$ and $20 \mathrm{mM}$ ) of copper ion solution $\left[\mathrm{Cu}\left(\mathrm{NO}_{3}\right)\right]_{2}$ before inserting the substrate into the given test tube shown in Fig. S3a. After Annealing Method: After growing the DNA DX thin films on the glass substrate, the appropriate amount of $1 \mathrm{M}$ concentration of 
$\mathrm{Cu}^{2+}$ was added and then incubated at room temperature for 24 hours (Figs. S3 b and $\mathrm{S} 3 \mathrm{c})$ ).

AFM imaging. For atomic force microscope (AFM) imaging, a substrate-assisted grown DNA sample was placed on a metal puck using instant glue. A total of $30 \mu \mathrm{L}$ of $1 \times \mathrm{TAE} / \mathrm{Mg}^{2+}$ buffer was then pipetted onto the substrate and another $30 \mu \mathrm{L}$ of $1 \times \mathrm{TAE} / \mathrm{Mg}^{2+}$ buffer was dispensed into a silicon nitride AFM tip (Veeco Inc.). AFM images were obtained by Multimode Nanoscope (Veeco Inc.) in the liquid tapping mode.

SQUID measurement. Before using superconducting quantum interference device (SQUID) to measure the magnetic properties, the samples were rinsed with DI water, followed by slowly blowing nitrogen gas to remove the excess $\mathrm{Cu}^{2+}$ and DNA residues from the surface of $\mathrm{Cu}^{2+}$-modified DNA thin films. Magnetization measurements at temperature ranging from $8-300 \mathrm{~K}$ were performed to understand the magnetic characteristics of the $\mathrm{Cu}^{2+}$-modified DNA complexes.

1. Geert, L. J. A. R. A New Twist on Spintronics. Science 331, 864-365 (2011).

2. Bader, S. D. \& Parkin, S. S. P. Spintronics. Annu. Rev. Cond. Mat. Phys. 1, 71-88 (2010).

3. Braun, E., Eichen, Y., Sivan, U. \& Ben-Yoseph, G. DNA Templated Self-Assembly of a Conductive Wire Connecting Two Electrodes. Nature 391, 775-778 (1998).

4. Rakitin, A. et al. Metallic Conduction through Engineered DNA: DNA Nanoelectronic Building Blocks. Phys. Rev. Lett. 86, 3670-3673 (2001).

5. Nam, J. M., Thaxton, C. S. \& Mirkin, C. A. Nanoparticle-Based Bio-Bar Codes for the Ultrasensitive Detection of Proteins. Science 301, 1884-1886 (2003).

6. Lu, Y., Goldsmith, B. R., Kybert, N. J. \& Johnson, A. T. C. DNA-decorated graphene chemical sensors. Appl. Phys. Lett. 97, 083107-3 (2010).

7. Lewis, F. D. DNA molecular photonics. Photochem. Photobiol. 81, 65-72 (2005).

8. Seeman, N. C. DNA in a material world. Nature 421, 427-431 (2003).

9. Yan, H. et al. DNA-templated self-assembly of protein arrays and highly conductive nanowires. Science 301, 1882-1884 (2003).

10. Steckl, A. J. DNA - a new material for photonics? Nat. Photonics 1, 3-5 (2007).

11. Tanaka, K., Tengeiji, A., Kato, T., Toyama, N. \& Shionoya, M. A Discrete Self-Assembled Metal Array in Artificial DNA. Science 299, 1212-1213 (2003).

12. Lee, J. S., Latimer, L. J. P. \& Reid, R. S. A cooperative conformational change in duplex DNA induced by $\mathrm{Zn}^{2+}$ and other divalent metal ions. Biochem. Cell Biol. 71, 162-168 (1993).

13. Aich, P. et al. M-DNA: a complex between divalent metal ions and DNA which behaves as a molecular wire. J. Mol. Biol. 294, 477-485 (1999).

14. Brancolini, G. \& Di Felice, R. Electronic properties of metal-modified DNA base pairs. J. Phys. Chem. B 112, 14281-14290 (2008).

15. Zwolak, M. \& Di Ventra, M. DNA spintronics. Appl. Phys. Lett. 81, 925-927 (2002).

16. Lee, K. et al. A two-dimensional DNA lattice implanted polymer solar cell. Nanotech. 22, 375202-6 (2011).
17. Porath, D., Cuniberti, G. \& Di Felice, R. Charge Transport in DNA-Based Devices. Top. Curr. Chem. 237, 183-227 (2004).

18. Hamada, S. \& Murata, S. Substrate-assisted assembly of interconnected singleduplex DNA nanostructures. Angew. Chem. Int. Ed. 48, 6820-6823 (2009).

19. Lee, J. et al. Coverage control of DNA crystals grown by silica assistance. Angew. Chem. Int. Ed. 50, 9145-9149 (2011).

20. Kim, B., Amin, R., Lee, J., Yun, K. \& Park, S. H. Growth and restoration of a T-tile-based 1D DNA nanotrack. Chem. Commun. 47, 11053-11055 (2011).

21. Winfree, E., Liu, F., Wenzler, L. A. \& Seeman, N. C. Design and self-assembly of two-dimensional DNA crystals. Nature 394, 539-544 (1998).

22. Lee, J. et al. Size-controllable DNA rings with copper-ion modification. Small $\mathbf{8}$, 374-377 (2012).

23. Park, S. H., Prior, M. W., LaBean, T. H. \& Finkelstein, G. Optimized fabrication and electrical analysis of silver nanowires templated on DNA molecules. Appl. Phys. Lett. 89, 033901-3 (2006)

24. Moreno-Herrero, F., Colchero, J. \& Baro, A. M. DNA height in scanning force microscopy. Ultramicroscopy 96, 167-174 (2003).

25. Nakamae, S., Cazayous, M., Sacuto, A., Monod, P. \& Bouchiat, H. Intrinsic Low Temperature Paramagnetism in B-DNA. Phys. Rev. Lett. 94, 248102-4 (2005).

26. Omerzu, A. et al. Strong Correlations in Highly Electron-Doped Zn(II)-DNA Complexes. Phys. Rev. Lett. 104, 156804-4 (2010).

\section{Acknowledgments}

This work was supported by the National Research Foundation (NRF) of Korea grant (2012-005985), (2012R1A6A1040282) to S.H.P. and by Mid-career Researcher Program (2010-0029136) to W.N.K. funded by the Korea government (MEST).

\section{Author contributions}

D.S.R. conceived and initiated this study. D.S.R. prepared the samples, took AFM images; D.S.R. and N.H.L. collected magnetic data. All authors contributed to the data analysis. D.S.R. wrote the manuscript with contributions from all authors. W.N.K. and S.H.P. supervised the research.

\section{Additional information}

Supplementary information accompanies this paper at http://www.nature.com/ scientificreports

Competing financial interests: The authors declare no competing financial interests.

License: This work is licensed under a Creative Commons

Attribution-NonCommercial-NoDerivs 3.0 Unported License. To view a copy of this license, visit http://creativecommons.org/licenses/by-nc-nd/3.0/

How to cite this article: Dugasani, S.R. et al. Magnetic Characteristics of Copper Ion-Modified DNA Thin Films. Sci. Rep. 3, 1819; DOI:10.1038/srep01819 (2013). 